\title{
فصاحة القرآن الثابتة والتطور اللغوي المتغير
}

\author{
Ali Burhan \\ Institut Agama Islam Negeri Pekalongan \\ aliburhan77@yahoo.com \\ DOI: http://dx.doi.org/10.18326/lisania.v1i1.90-108
}

\begin{abstract}
Fashahah according to the classic scholars is sealed by period, place, and vocabularies with certain conditions, while it according to contemporary scholars is a process of renewable development. In modern linguistics, it reveals the activities and thought of the modern Arab nation. It continuously describes its function as a different transmitter of the Arabic functions according to classic scholars which is more dynamic and not static. The result concludes that the classical Arab in the Qur'an is in peak not only as a means of conveying the thought, but also becomes the religious and unifying language of Arab nations with its various specifications. The process of evolution occurring in Arabic Language includes its pronunciation, structure of grammar, and dilalah.
\end{abstract}

Keywords: Fluency, Al-Qur'an, language development

\begin{abstract}
Abstrak
Fashahah menurut ulama klasik tersekat oleh masa, tempat, dan kosa kata-kosa kata dengan syarat tertentu, sedangkan menurut ulama kontemporer merupakan proses pengembangan yang bersifat terbarukan. Fashahah dalam ilmu linguistic modern mengungkapkan kegiatan dan pemikiran bangsa Arab modern. Hal ini berkesinambungan dalam menggambarkan fungsinya sebagai alat penyampai yang berbeda dari fungsi bahasa Arab versi ulama klasik dan lebih bersifat dinamis tidak statis. Hasil dari tulisan ini menyimpulkan bahwa bahasa Arab klasik yang ada pada AlQur'an berada pada puncaknya tidak hanya sebatas sebagai alat penyampai pikiran, namun lebih dari itu menjadi bahasa agama dan pemersatu bangsa-bangsa Arab dengan berbagai spesifikasi yang ada di dalamnya. Proses evolusi yang terjadi dalam bahasa Arab mencakup sisi pelafalan, struktur tata bahasa, dan dilalahnya.
\end{abstract}

Kata kunci: kefasihan, Al-Qur'an, perkembangan bahasa 


\section{مقدمة}

كان الشعب العربي معروفا بشدة حفظه وحفاظه على لغته منذ العصر الجاهلي الذي اشتهروا فيه بالتباهي بمدى معرفتهم لعلو الذوق اللغوي السليقي لديهم وتطبيق نواحي هذه المعرفة الجمالية خاصة في نظم الشعر الجاهلي. فعلى الرغم من صعوبة تعلم اللغة العربية

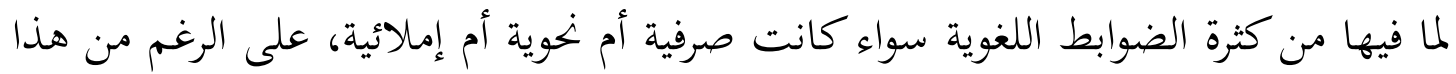
كله فإن العرب قد أبدعوا في التعمق في لغتهم، فجرى القدر الإلهي السماوي بأن القرآن

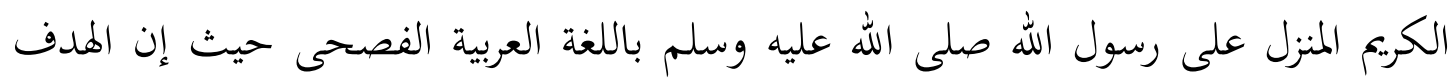
منه - وهو الظاهر الملموس التاريخي - التحدي على العرب الذي كان معروفا ببراعتهم بلغتهم في الإتيان بمثله أو مثل أقصر سورة منه فعجزوا عن محاكاة القرآن لما رأوا فيه من علو الشأن وإحكام الأسلوب وروعة المعاني، ووصف الوليد بن المغيرة القرآن - وكان كافرا جاحدا برسالة محمد صلى الله عليه وسلم - بأنه يعلو ولا يعلى عليه.

فقد ورد في الحميث النبوي الشريف: عن ابن عباس رضي الله عنهما أن الوليد بن

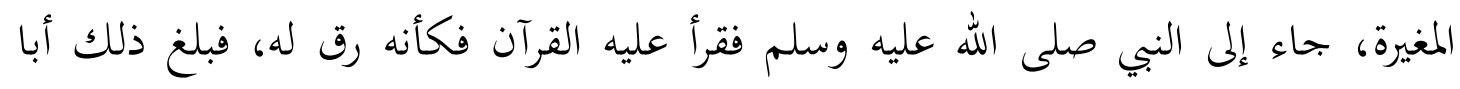

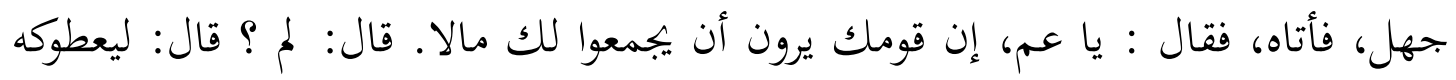

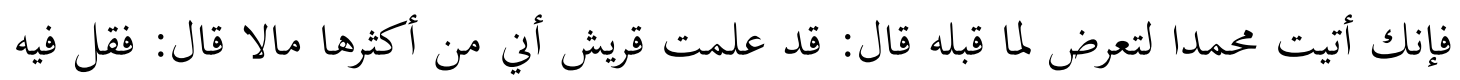

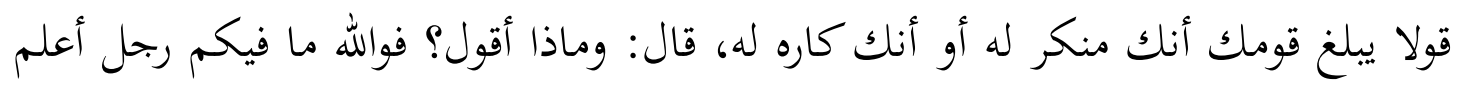
بالأشعار مني، ولا أعلم برجزه ولا بقصيدته مني، ولا بأشعار الجحن. والله ما يشبه الذي يقول

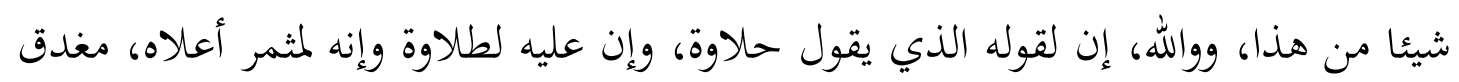
أسفله، وإنه ليعلو وما يعلا، وأنه ليحطم ما تحته (رواه البيهقي في دلائل النبوة في باب جماع وإنه

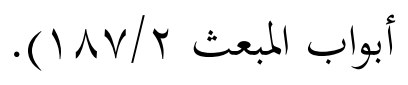

فألفاظ القرآن هي الألفاظ التي يستعملها العرب في نثرهم وشعرهم وتمتاز بالدقة البالغة في اختيار اللفظ ويتفرد بسمو التراكيب وعلو الطريقة في اختيارها. وخحالف القرآن هُج العرب وطريقتهم في شيء واحد، هو ذلك البناء الكلي للآية، وللآيات، وللسور، فهو متميز ببناء فريد لم يكن قبله، ولم يأت بعده ما يماثله. 
قال أبو بكر الباقلاني: إنه نظم خارج عن جميع وجوه النظم المعتاد في كلامهم، ومباين لأساليب خطائم، ومن ادعى ذلك لم يكن له بد من أن يصحح أنه ليس من قبيل

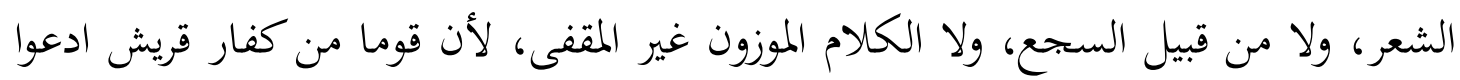

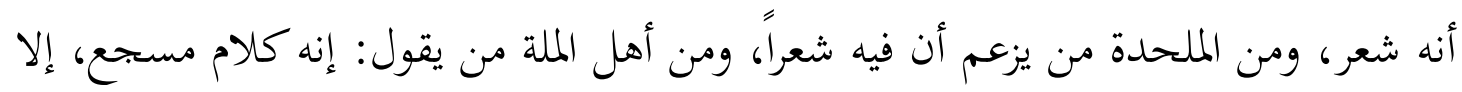

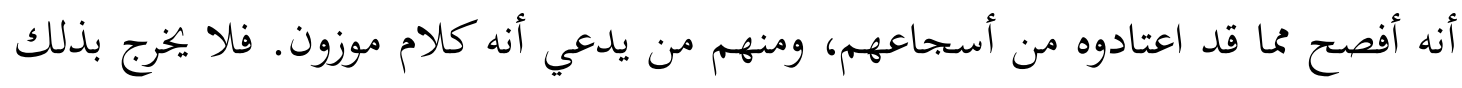

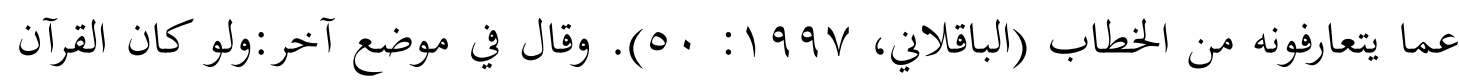

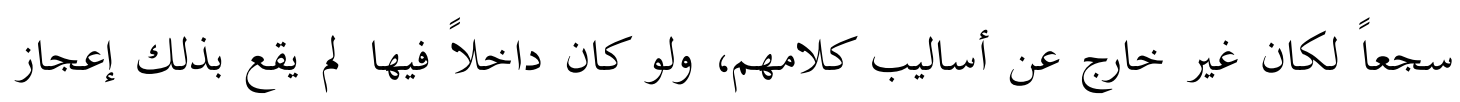
(الباقلاني، 99 V 1 V V ). وقال في موضع ثالث: فاستدللنا بتحريهم في أمر القرآن على خروجه عن عادة كلامهم، ووقوعه موقعا يخرق العادة، وهذه سبيل المعجزات (الباقلاني، . ( $7 \leqslant: 199 \mathrm{~V}$ فالقرآن نزل باللغة العربية لأمرين أساسيين: أولمما الإعجاز؛ لإثبات صدق الرسالة، وذلك للقوم الذين نزل القرآن فن بيئتهم التى نشأ فيها الرسول وبدأ الدعوة، ولغيرهم من لإبن الناس بما يحويه من معلومات وتشريعات هى أصدق المعلومات وأحكم التشريعات، والثانى الهدايةلكل الناس التي يحملها من تلقوه باللغة العربية، ثم يترجمون هذه الهداية إلى غيرهم.وهذا

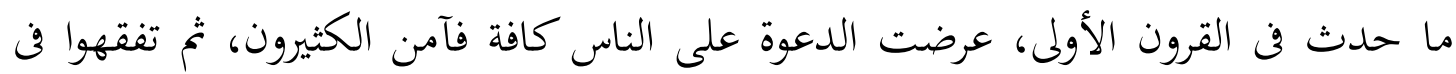

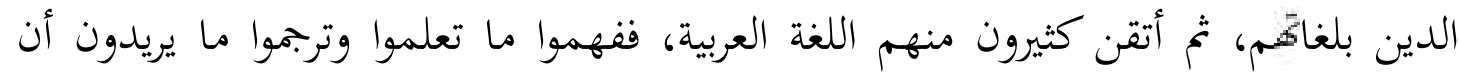

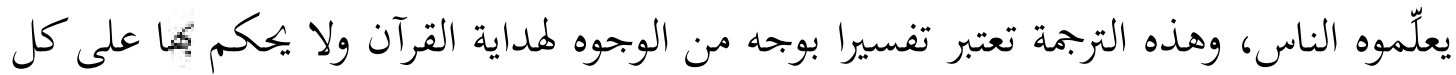
ما في القرآن من معان. ووظيفة اللغة العربية كلغة القرآن تتركز في توحيد الأمة الإسلامية، التى دخل فيها الفارسي والحبشي والرومي في العصر الأول من الدعوة الإسلامية، فنسوا لغتهم الأصلية،

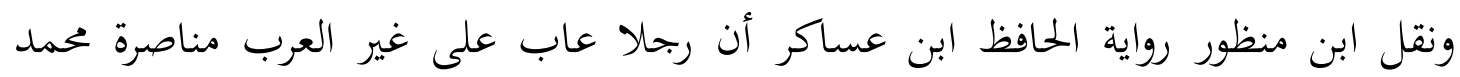

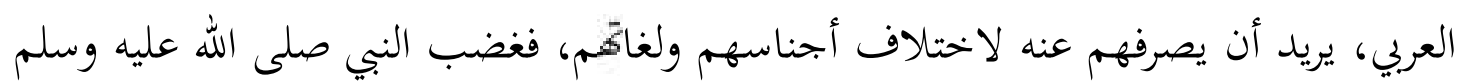

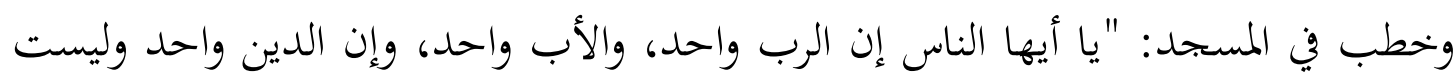

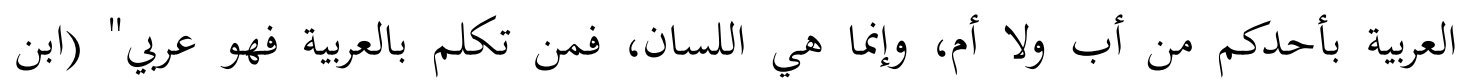

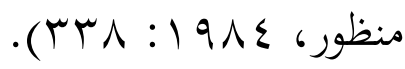


ووجوه الإعجاز القرآني تتنوع في شتى ميادين الدراسات الإسلامية كعلم الأصول والتفسير والبلاغة ولا يزال البحث يكشف عن جديد وبخاصة في هذا العصر الذي ازدهرت

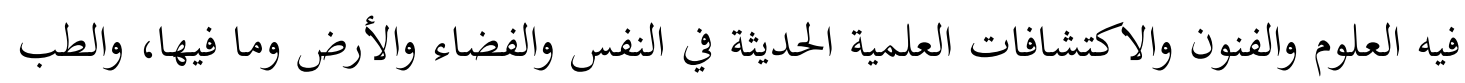
ونظائره من العلوم الإنسانية والعملية، ويدور الإعجاز القرآني كما يراه القدماء حول الوجوه الآتية:

$$
\text { ا ـ الأخبار والوعود الصادقة. }
$$

r. الإخبار عن الغيوب التي وقعت كما أخبر عنها القرآن. r. فصاحة ألفاظه وسلامة معانيه وشرفها.

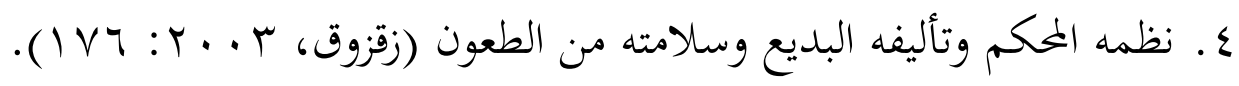

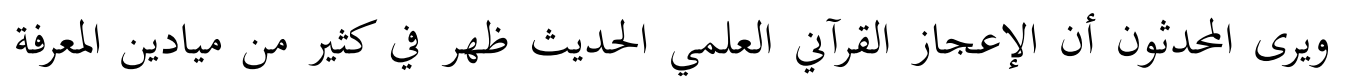

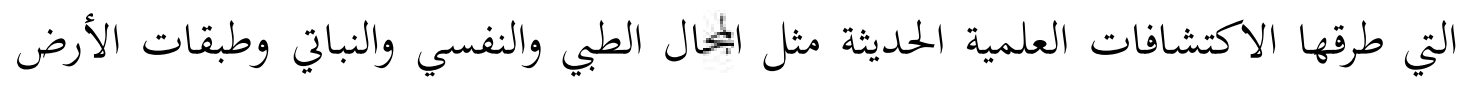

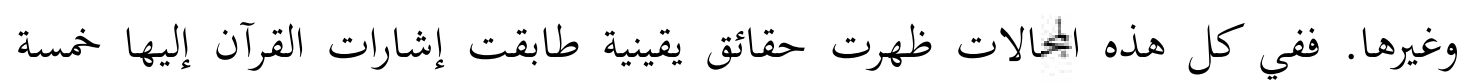

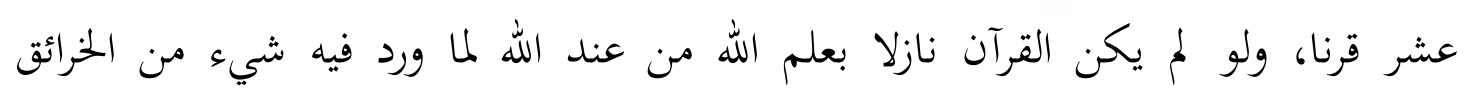
العظيمة. ومع هذه الحقائق العلمية التي تدل على إعجاز القرآن علميا ونظريا فهناك حملة قام

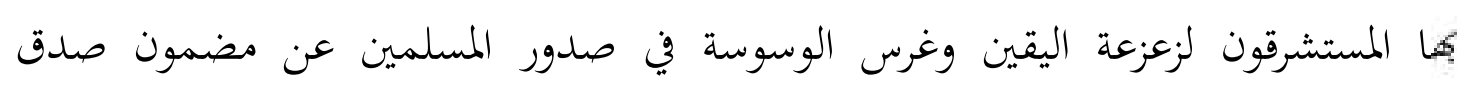

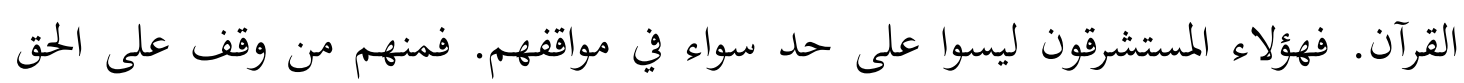

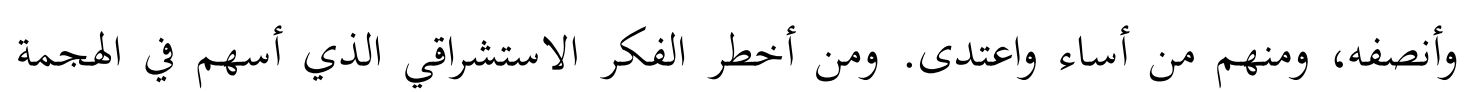

$$
\text { على القرآن من خلال الدراسات القرآنية: }
$$

• كتاب تيودور نولدكه (تاريخ القرآن)، وهو من أهم الكتب التي ألفها المستشرقون في

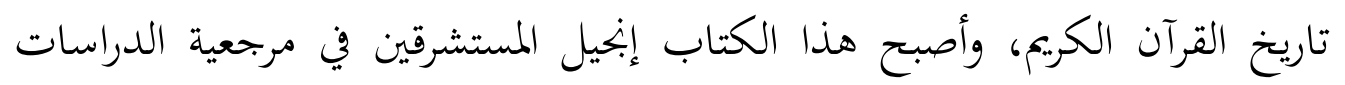
القرآنية. • كتاب جولدتسهير الذي ترجمه الدكتور عبد الحليم النجار تحت عنوان: مذاهب التفسير الإسلامي. 
• كتاب جون وانسبرو بعنوان: دراسات قرآنية: مصادر الكتب المقدسة وطرق تفسيرها، ويعد هذا الكتاب من أخطر كتب المستشرقين حيث تأثر به جانب كبير ممن جاءوا بعده في البحث القرآي أو التاريخ الإسلامي عامة. • كتاب دون ريتشاردسون بعنوان أسرار القرآن الذي يخلط بين الدراسات القرات القرآينة والسياسة. • كتاب نيل روبنسون بعنوان اكتشاف القرآن: مقاربة معاصرة لنص محجب. • كتاب كريستوف لوكسنبورج بعنوان: كتاب سريانية - آرامية للقرآن: مساهمة في

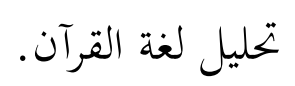
ـ كتاب ابن وراق بعنوان لماذا أنا لست مسلما؟ حيث إن المؤلف يقدم نقدا لاذعا وقويا ضد الإسلام في منهجية علمية في العرض دون الصدق في المضمون (داود،

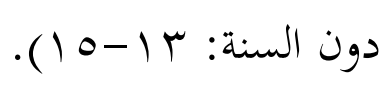

والمدهش العجيب أن القرآن كلما اشتد الهجوم عليه من معارضيه ومنكريه ازداد تألقا وقوة، فحقائق القرآن الخالدة تدحض الزيف والافتراء وكل ما يثيره أعداء القرآن من شهبات.

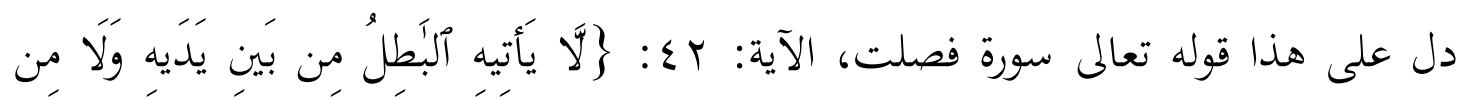

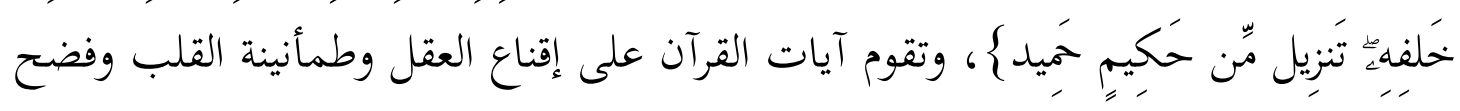

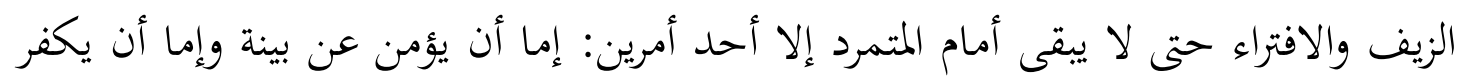

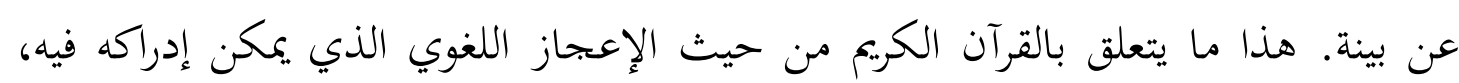

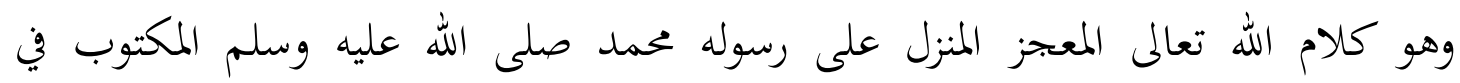
المصاحف المنقول بالتواتر المتعبد بتلاوته.

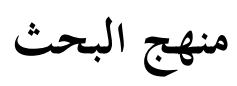

هـذا البحث هو مـن ضمن البحث النوعي، والبحثث النوعي كما قال مايكل قوين

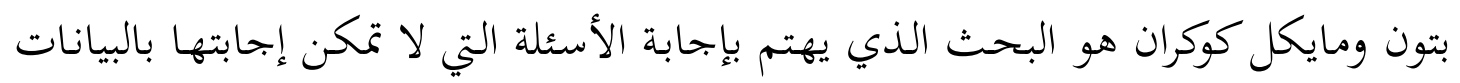

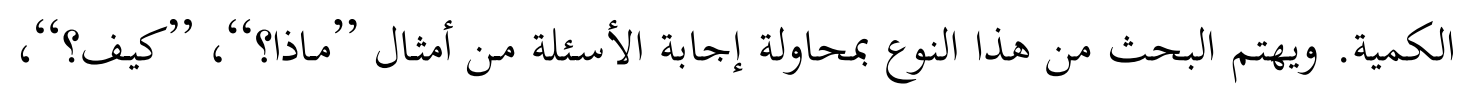

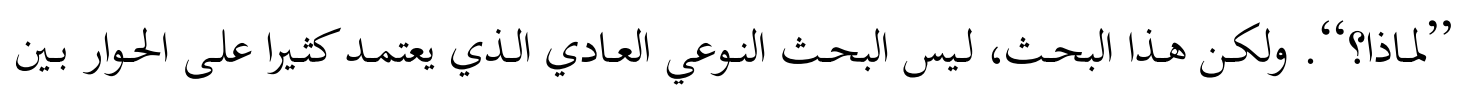

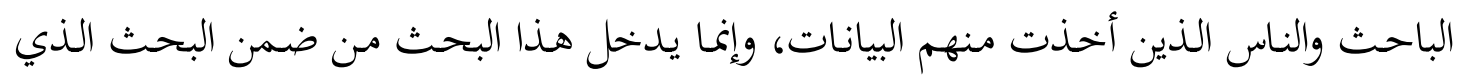


يعتمد على الكتب والمقالات أي البحث المعتمد على الكتابات، سماه البختمع الغربي المتي based research diterature review) الكتابات له خطة علمية أكثر من الثاني. والموضوع لهذا البحث هو فصاحة القرآن والتطور اللغوي. هذا الموضوع يدور حول اللغة العربية الفصيحة في القرآن الكريم وتطور اللغة اللعرية للعرب. وذلك بإضافة عدة أفكار المتخصصين في هذا البحال.

والمدخل الذي يسير عليه الباحث هو المدخل الاستقرائي (inductive approach) والبحث الاستقرائي هو البحث الذي يحاول الكشف النمط أو النظام من خلال الملاحظة، وتطوير البيانات والنظريات لهذا المنهج من خلال سلسلة من التحليل. والاستقراء هو ضد الاستدلال. البحث الاستدلالي يبدأ بالنظريات ثم ملاحظة تطبيق هذه النظريات في الميدان

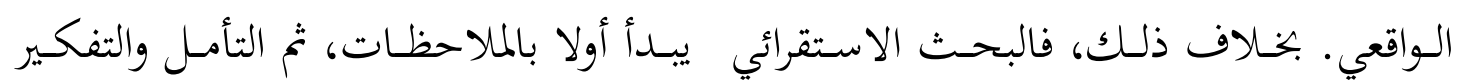

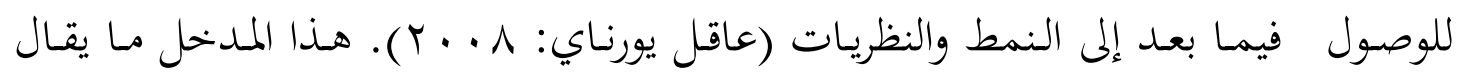

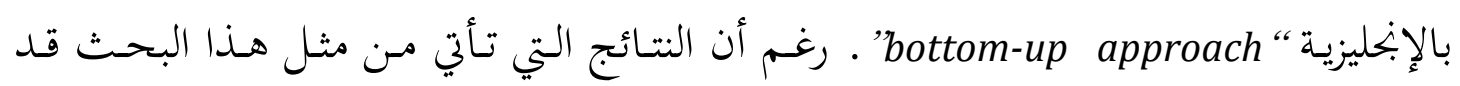
يكون غير معين إلى درجة ما. بكائ. تكون مصادر بياناتَا الأولية كتابات تتعلق بموضوع البحث. وهناك مصادر أو مراجع

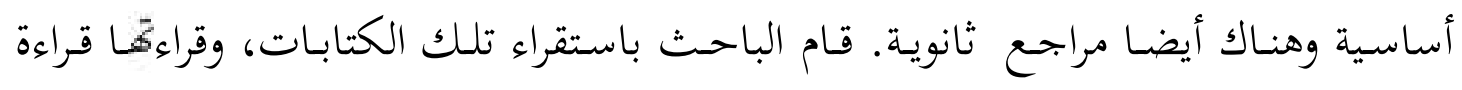

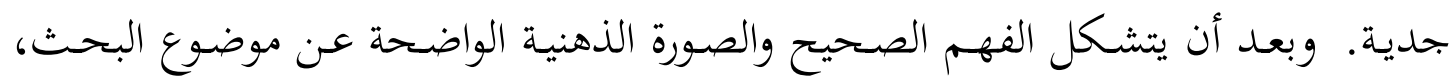

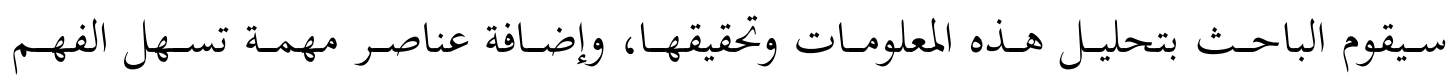
والتصور للقارئ. بعد أن قام الباحث بقراءة المراجع الأساسية والثانوية، أخذ الباحث المعلومات الهامة التي تتعلق بالموضوع، ثم يقوم بتحليلها وبياها باستخدام النظريات التي تم جمعها في الإطار النظري. 


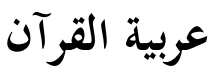

لقد نزل القرآن الكريم باللغة العربية. فقد بلغ غاية الفصاحة وهناية البلاغة بين قوم لا يخلون من جملتهم من شاعر فحل، أو خطيب مصقع. وكان القرآن الكريم جامعا لفنون

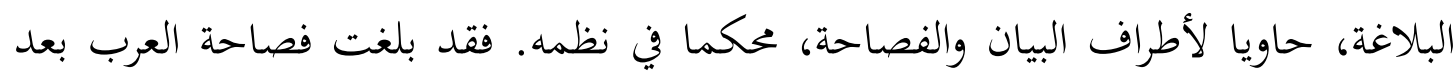

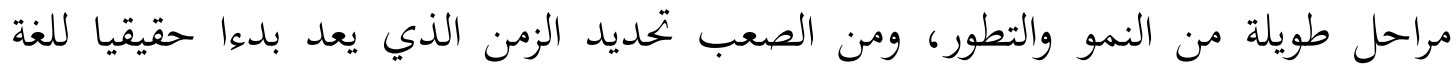
العربية الفصحى حيث لم يرد النقوش الكافية التي تدل على بدء فصاحة العرب. فعلماء

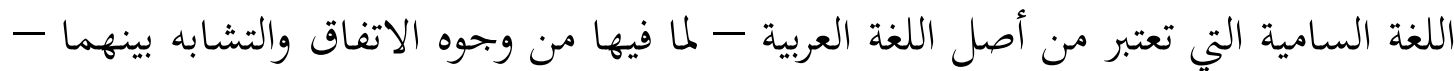

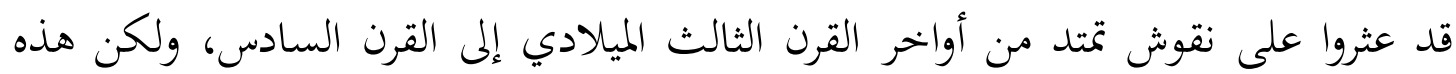

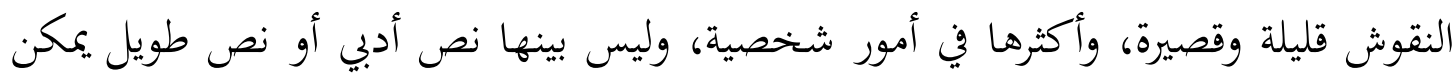

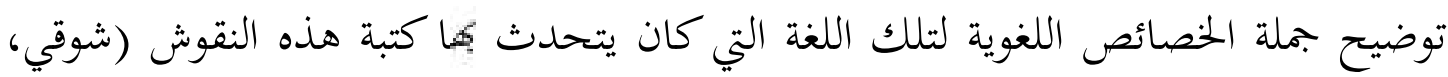

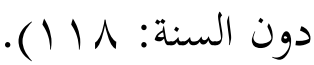
والقرآن الكريم إذ جاء بأصفى ألفاظ اللغة العربية وأعذهما وأفصحها، فلا يمكن أن

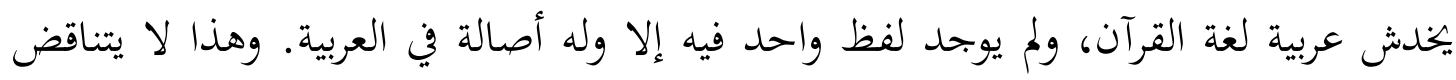

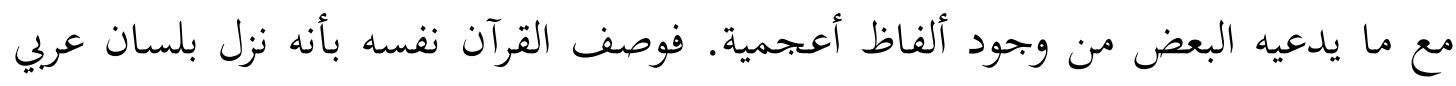

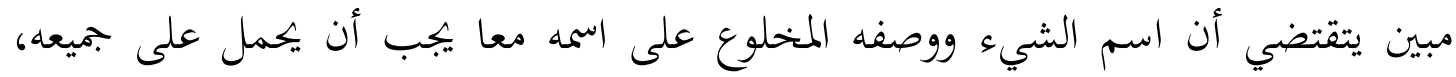
وعليه يكون القرآن جميعه عربيا. فقد زعم المشككون أن ورود بعض الكلمات الأعجمية فيه الكيه

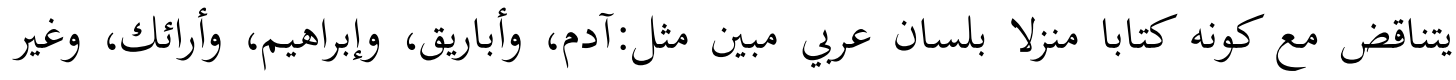

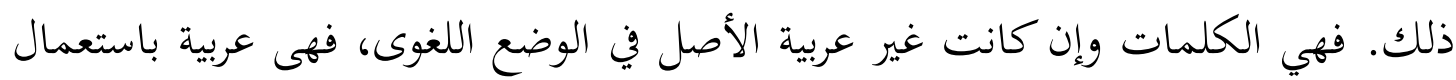

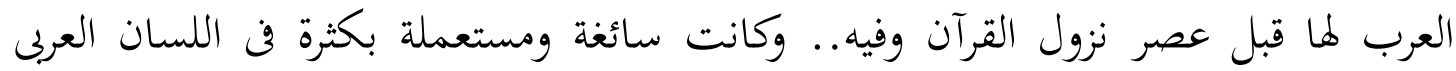

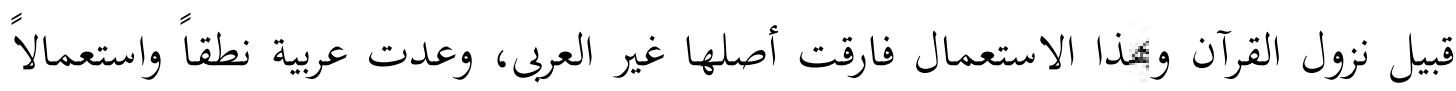
وخطا.

واللغة العربية كبقية اللغات البشرية الأخرى - قبل أن تكون لغة الوحي من السماء المتعبد بدراستها - هي وسيلة للتعبير وأداة التوصيل والتواصل والتفاهم بين البشرية.

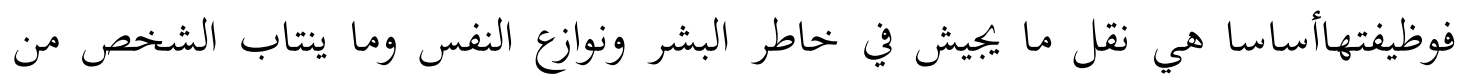
شعور دافق وخلجات باطنة وظاهرة، فتتنقل إلى طالبها بطريقة الأصوات ويعبر عنها 
بالأحرف الألفاظ، ومن ثم عرف ابن جني اللغة بأهها أصوات يعبر بها كل قوم عن أغراضهم

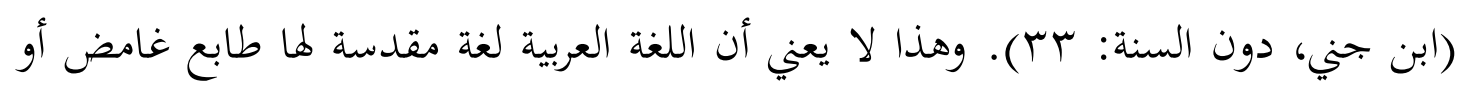

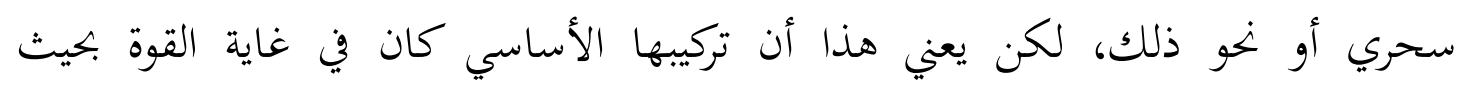

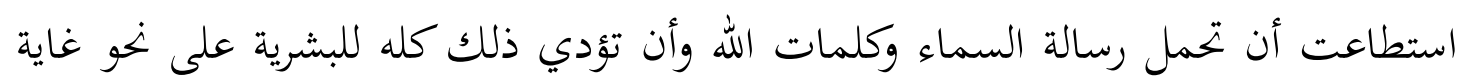
في القدرة والاقتدار.

فنزول القرآن الكريم بلغة العرب الذين كانوا ينظمون فيها أشعارهم ويلقون فيها خطبهم ويتخاطبون بها فيما بينهمدليل لا شك فيه عن التحدي على الأمة العربية فعجزوا

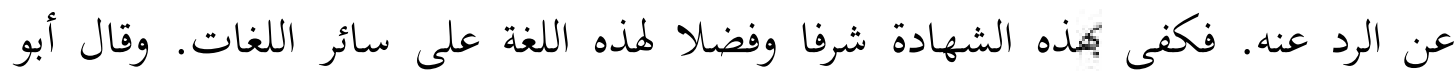

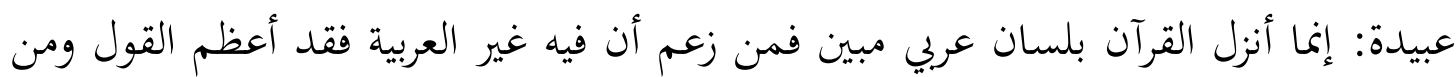

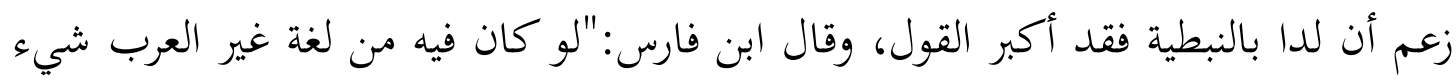

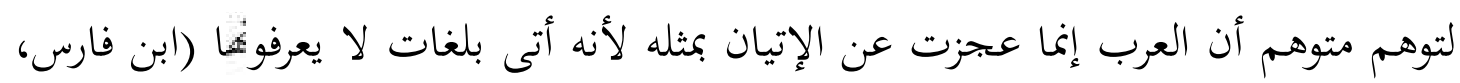
( ) قال ابن كثير: "وأما القرآن فجميعه فصيح في غاية فهايات البلاغة عند من يعرف

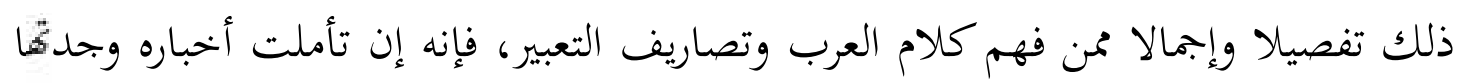

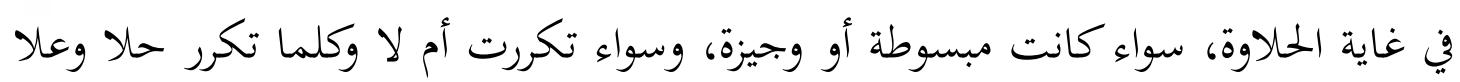

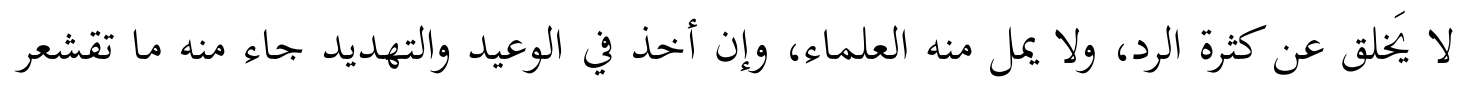

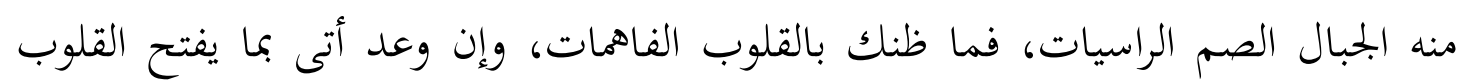
والآذان، ويشوق إلى دار السلام وبحاورة عرش الرممن" (ابن كثير، 1999 ا: . . ب).

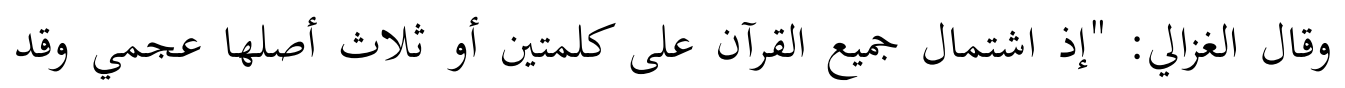

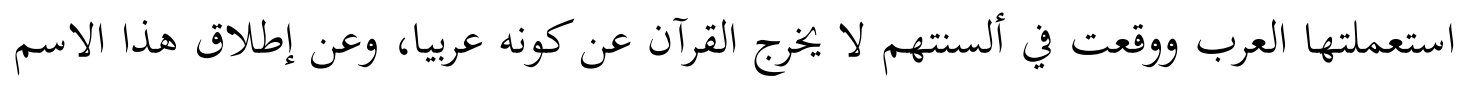

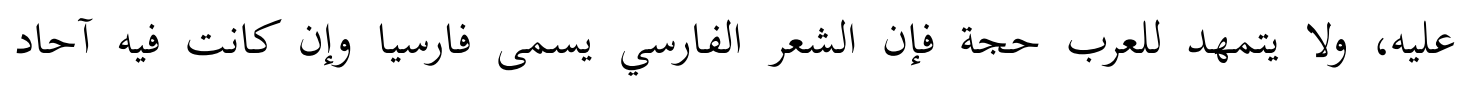

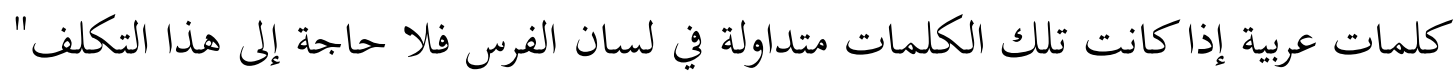

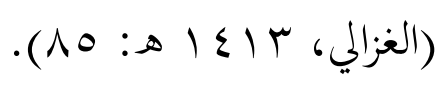

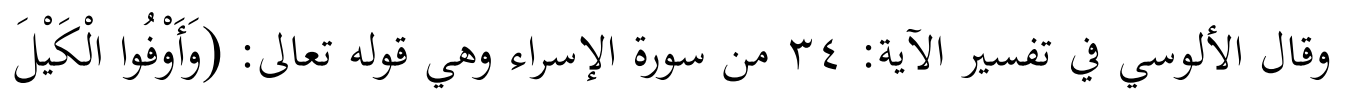

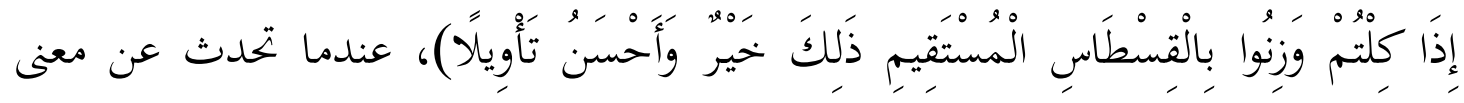


القسطاس: "... وعلى القول بأنه رومي معرب وهو الصحيح لا يقدح استعماله في القرآن

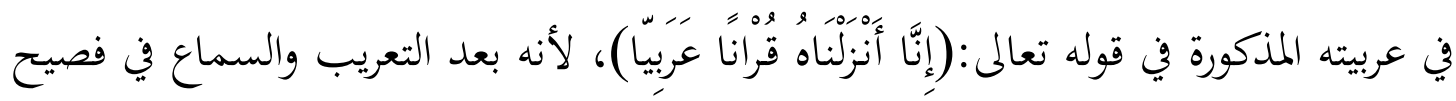
الكلام يصير عربياً فلا حاجة إلى إنكار تعريبه أو ادعاء التغليب أو أن المراد عربي الأسلوب. ترناه

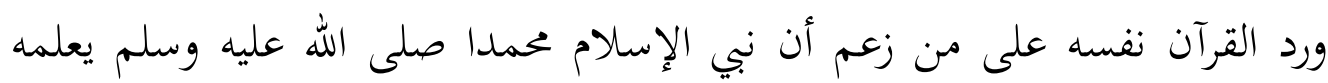

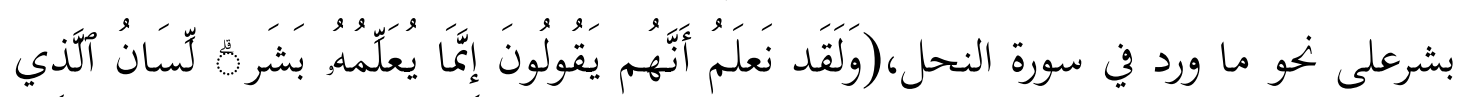

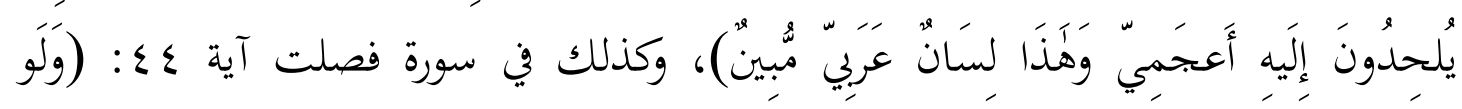

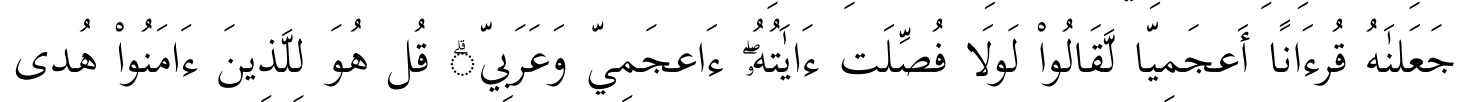

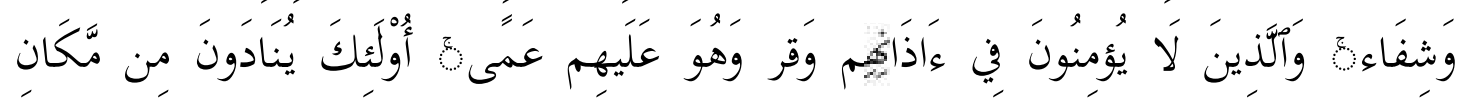
بعيد). (1) وتتمثل فصاحة اللغة العربية في شكل كامل النضج سواء من حيث الإعراب والتصريف والاشتقاق أو من حيث التنويع الواسع في الجموع والمصادر وحروف العطف

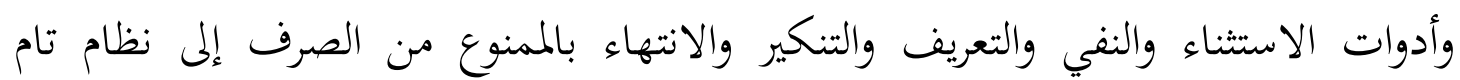
منضبط،إضافة إلى ذلك احتفاظها بحروف ومخارج، وهذا الأخير من خصائص اللغة العربية التي لم تحتفظ بها اللغة السامية وهي لغة الأم لها وأصل لها احتفاظا كاملا، وهي الثاء والخاء والذال والظاء والضاد والغين. فالقرآن الكريم له دوره في أقصى الأهمية في الحفاظ على اللغة العربية الفصحى والإبقاء عليها رغم كل عوامل الإحباط التي تحوطها حتى تكاد أن تتحول

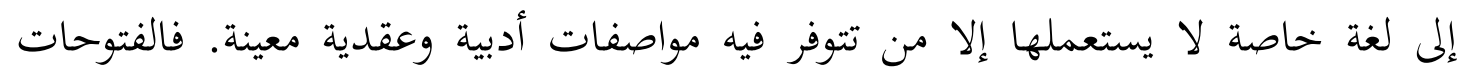
الإسلامية في الدول الأسيوية تشهد جهود المسلمين الذين يحملون دينهم إلى تلك المناطق وينشرون راية القرآن وعلموا تلك الشعوب خصائص اللسان العربي حتى استبدلته بلغاتها

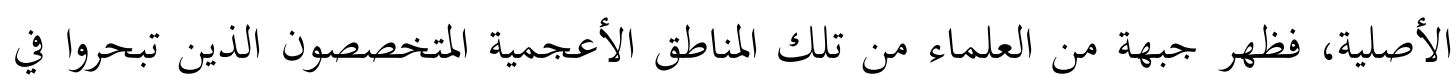
فنون العربية وصاروا أئمتها الذين يرجع إليهم ويفتون في مشكلاتها كسيبويه وابن سينا،

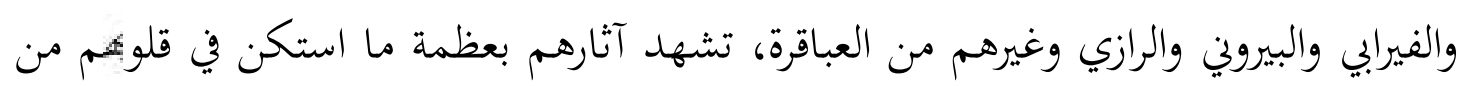
حب العربية وولاء للقرآن الكريم. فبقاء اللغة العربية راجع إلى الدفاع عن القرآن، لأن الدفاع عنه لكونه أصل الدين

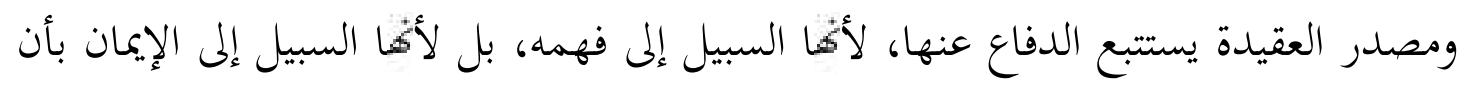


الإسلام دين الله، وأن القرآن من عنده. وأشار الأستاذ عباس محمود العقاد إلى أن إنسانية الإسلام وعالمية تشريعه ساعدت على انتشار العربية التي هي لغة كتابه (القرآن) الذي وحد في المؤمنين به مقاصد الضمائر والألسنة والأفكار على الرغم من اختلافهم في مواقع البلاد. يضاف إلى هذا أن الألفاظ التي ستخدمها القرآن صارت هي الأهم والأهى والأجمل والأكثر شيوعا وتداولا على الألسنة.فاللغة العربية كغيرها من لغات البشر خاضعة للتغير

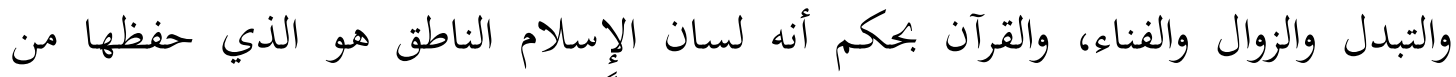
الضياع، لأنه جاء على وجه تحدى به العرب تحديا صارخا. ولو أن القرآن جاء كما جاء غيره من الكتب السماوية بحردا عن الإعجاز لما كان حتما على الناس أن يلزموا أنفسهم بحفظه. وقد وضع العلماء شروطا للحصول على رتبة الاجتهاد في الدين، منها إتقان اللغة العربية لأكها لغة القرآن الذي نزل بها، ولغة تحدث بها نبي الإسلام صلى الله عليه وسلم، فمن الضروري أن يشترط ذلك لمن بلغ رتبة الاجتهاد في علوم الدين.

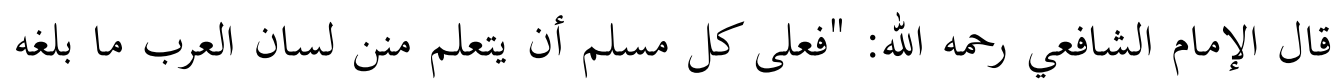

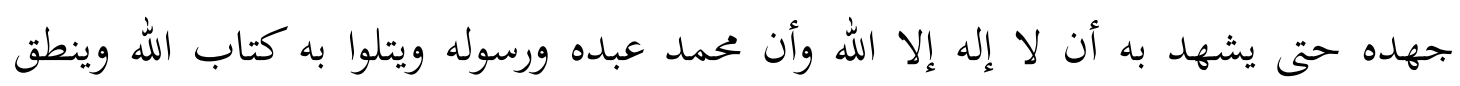
بالذكر فيما افترض عليه من التكبير وأمر به من التسبيح والتشهد وغير ذلك (الشافعي،

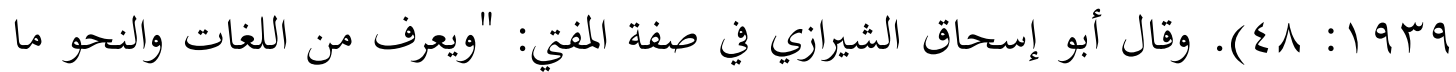

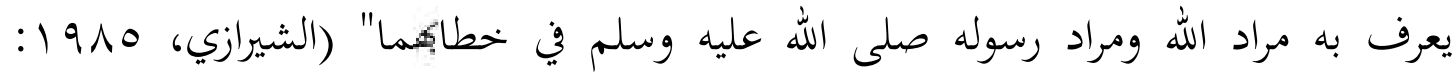
.$(1 \mathrm{TV}$ وقال الماوردي: "ويكون من أهل الاجتهاد إذا أحاط علمه بخمسة أصول... الخامس علمه بالعربية فيما تدعو الحاجة إليه من اللغة والإعراب، لأن لسان الكتاب والسنة

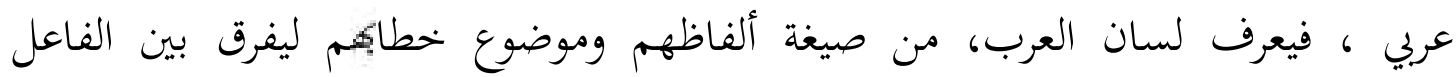

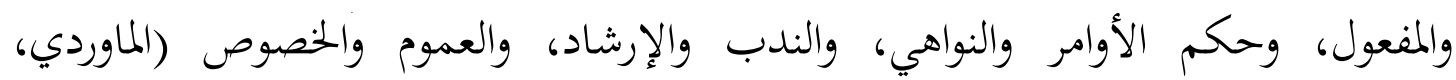
ـ99 19: • - - 10)، وقال في موضع آخر:"كان معرفة لسان العرب فرضا على كل مسلم من بجتهد وغير بجتهد. إلَا أن غير البحتهد يلزمه من فرضه ما اختص بتكليفه من الشهادتين 
وما تتضمن الصلاة من القراءة والأذكار ولا يلزمه معرفة ما عداه إلا بحسب ما يتدرج إليه في نوازله وأحكامه" (الماوردي، دون السنة: ـ ا I).

وقال ابن تيمية: "ومعلوم أن تعلم العربية وتعليم العربية فرض على الكفاية، وكان السلف يؤدبون أولادهم على اللحن، فنحن مأمورون أن نحفظ القانون العربي، ونصلح

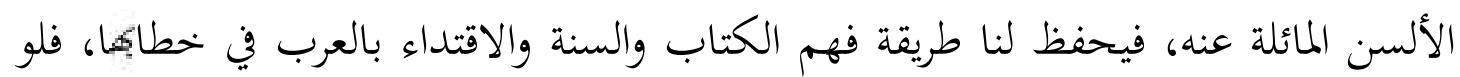

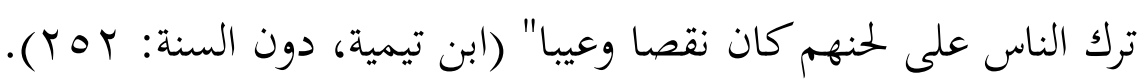
الفصاحة في العربية الفصحى لغة: وصف لمؤنث من فصُح يدل على التفضيل، يدور معنى هذه المادة

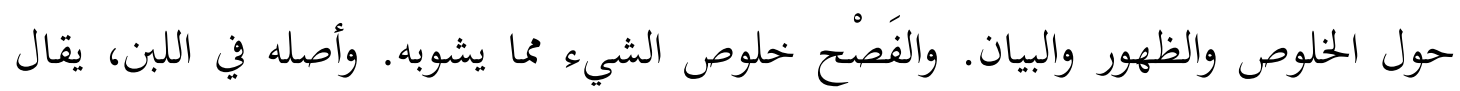
فصح اللبن، وأفصح فهو مفصح وفصيح إذا تعرى من الرغوة. ومنه استعير: فصح الرجل إذا

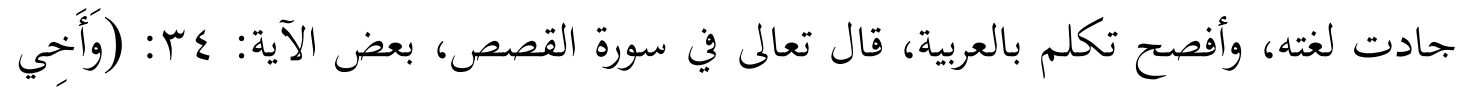

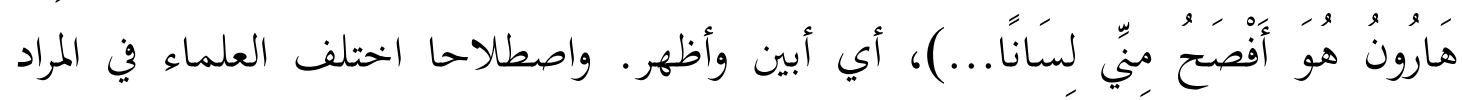
بالفصيح، فيرى كثير أنه ما كثر استعماله على ألسنة العرب الفصحاء.

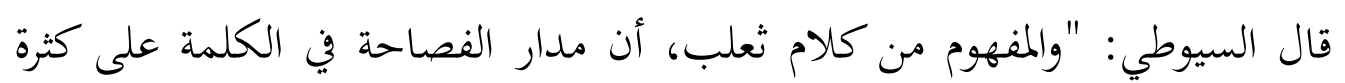

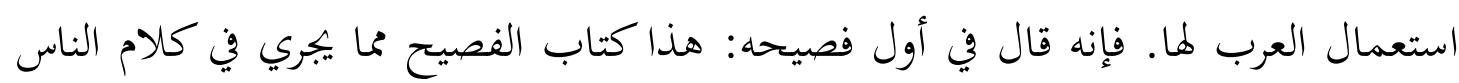
وكتبهم، فمنه ما فيه لغة واحدة والناس على خلافها، فأخبرنا بصواب ذلك، ومنه مالكه ما فيه

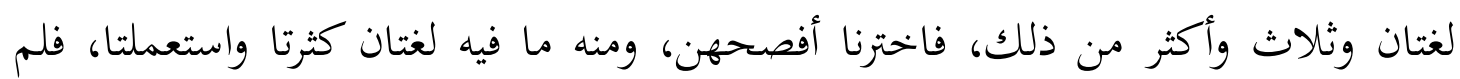

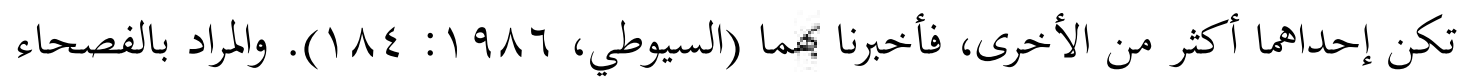

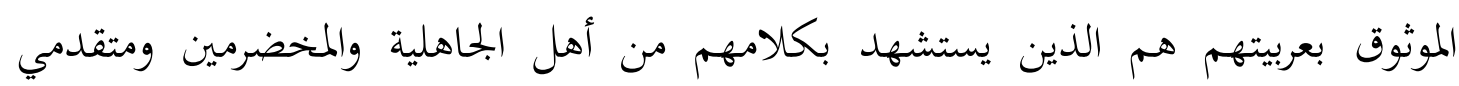

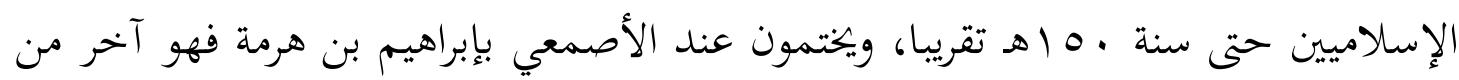

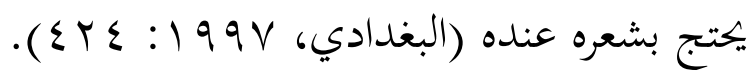
ويرى بعض اللغويين أن الفصيح لا يخضع لكثرة الاستعمال ولا لقلته، وإنما الفصيح

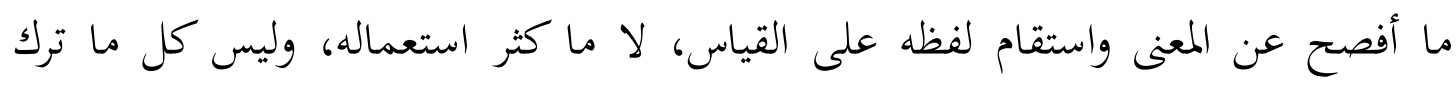
الفصحاء استعماله بخطإ، فقد يتركون استعمال الفصيح لاستغنائهم بفصيح آخر، أو لعلة

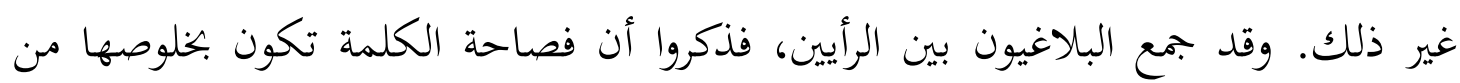


عيوب ثلاثة: تنافر الحروف والغرابة ومخالفة القياس. فإن كانت الكلمة متنافرة الحروف، مثل:

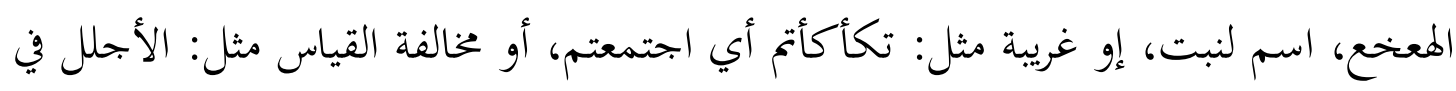

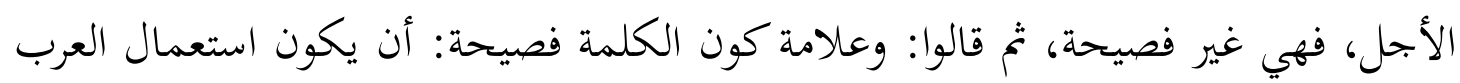

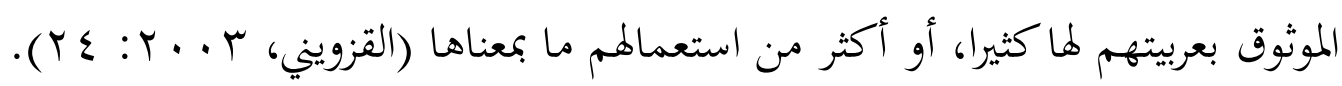

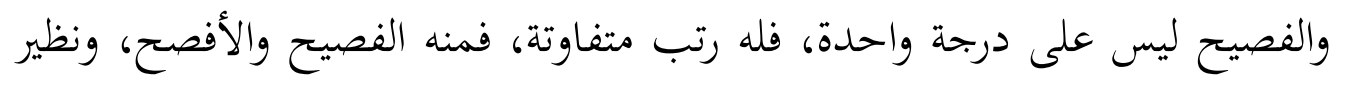

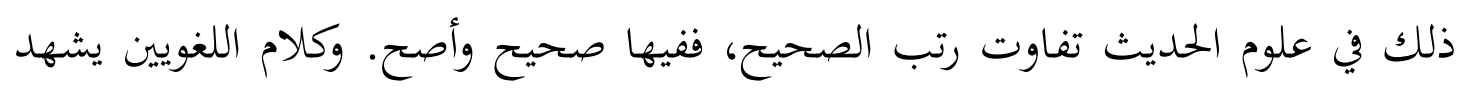
بذلك. ففي "ذيل الفصيح": وتشديخ النخل - أي شق بسره - أفصح من التشقيح. وبعَّح

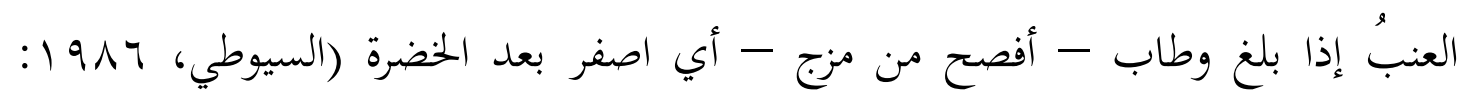

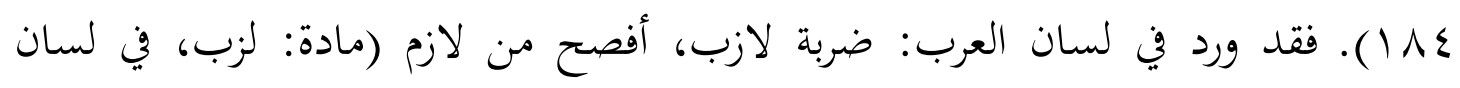

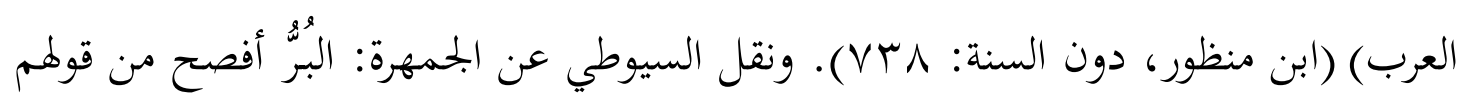

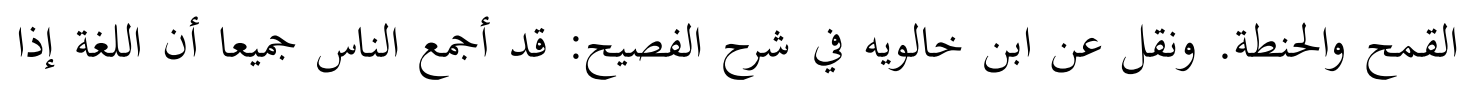
وردت في القرآن فهي أفصح مما في غير القرآن لا خحلاف في ذلك. وخلاف الفيح الفصيح إما ضعيف أو منكر أو متروك. فالضعيف ما انحط عن درجة الفصيح، والمنكر أضعف منه وأقل

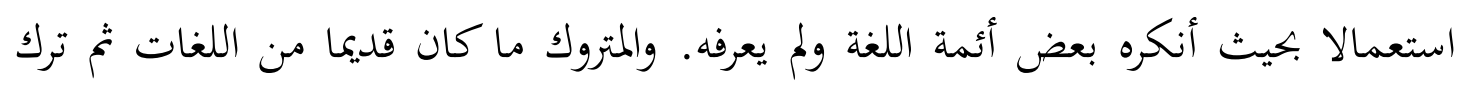

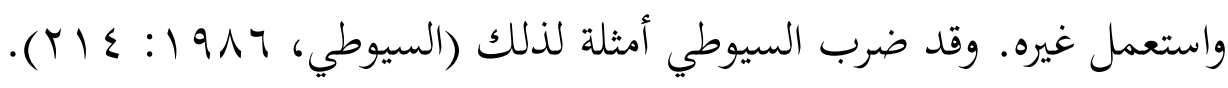

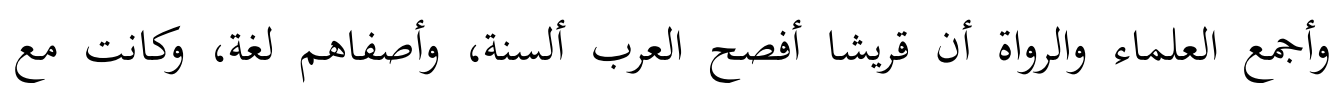
فصاحتها وحسن لغاتها ورقة ألسنتها إذا أتتهم الوفود من العرب تخيروا من كلامهم وأشعارهم أحسن لغاقهم وأصفى كلامهم، فاجتمع ما تخيروه من تلك اللغات نحائزهم إلى سلائقهم التي

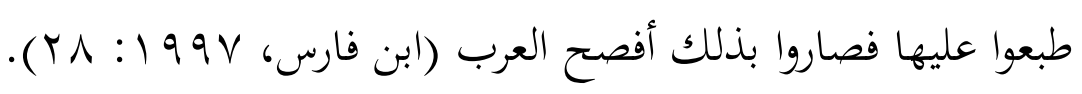
أهمية اللغة العربية الفصحى كانت العربية عند ظهور دين التوحيد لغة قبائل: لربيعة في شمال جزيرة العرب لهجة، ولتميم وقيس ومن انضاف إليهم في وسط الجزيرة لهجة، ولكنانة وهذيل وثقيف وخزاعة

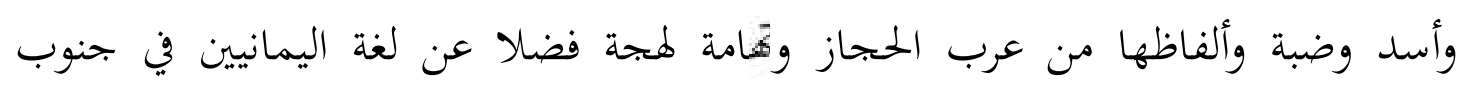
الجزيرة، وكانت لهجة القبيلة الواحدة تفترق عن لهجة غيرها في مادة اللغة وكيفية النطق بها.

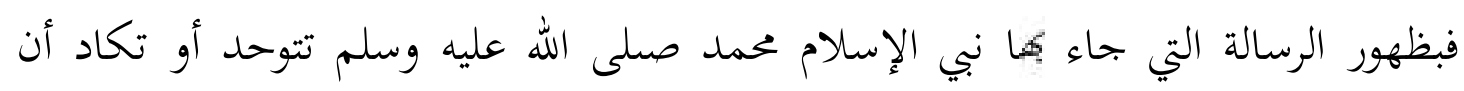


تتوحد تلك اللهجات في لهجة قريش التي كانت تمثل أرقى لهجات اللغة العربية ونزل القرآن

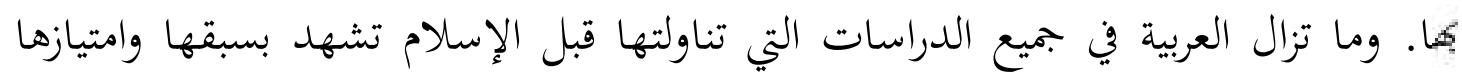
. (الجني، (190:)

ومن ثم يتضح أن من أهم الأسباب التي تدل على أهمية اللغة العربية الفصحى ما

ـ أن اللغة العربية الفصحى هي لغة بني الإسلام سيّدنا مُمّمد (صلى الله عليه وسلم)، ولا

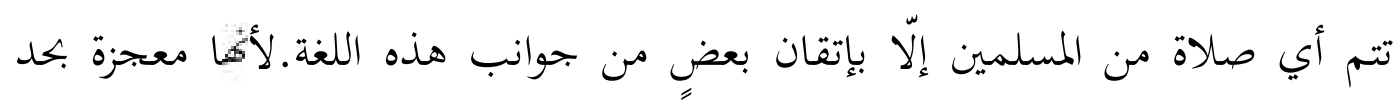

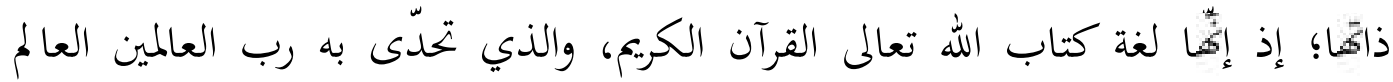

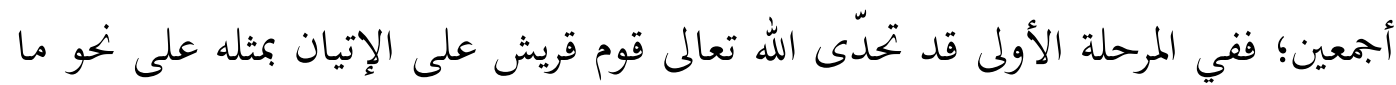

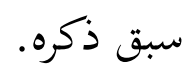

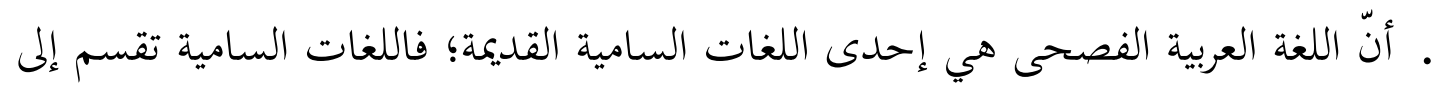

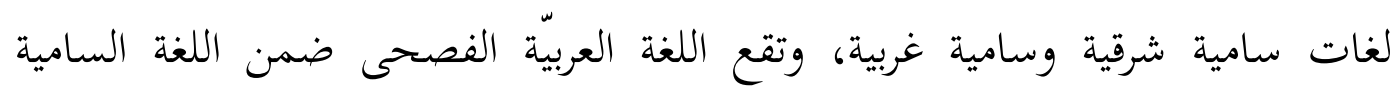

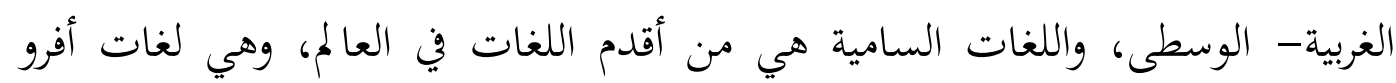

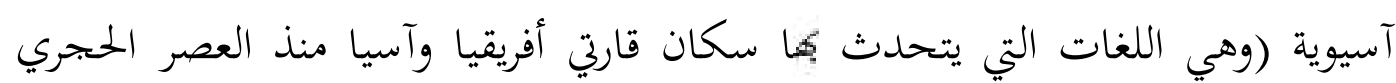
الحديث)، وهي الأكثر استخداماً من بين كلّ اللغات السامية.

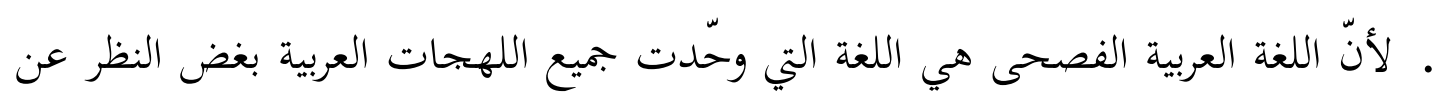

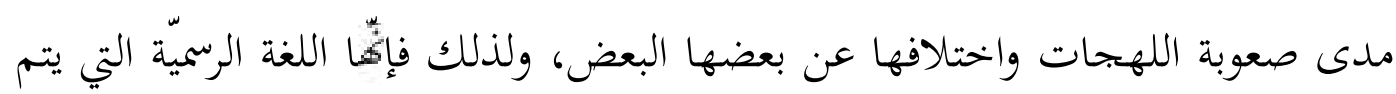

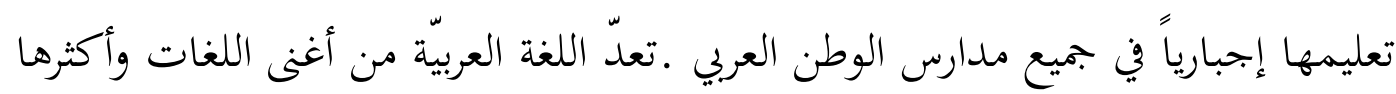

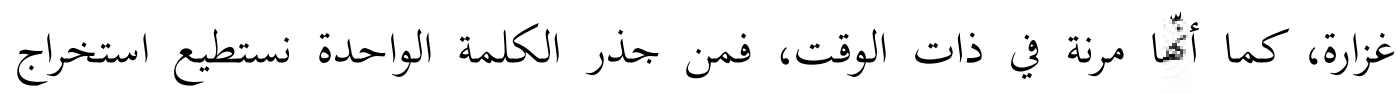

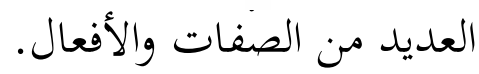




\section{تحديات العربية الفصحى في العالم الواقع}

كانت التحديات التي تواجهها اللغة العربية الفصحى ليست مقصورة في الشعب الأعجم الذين لا ينطقون ولا يعرفون شيئا عن اللغة العربية. بل إن الأمة العربية أو كثيرا منها قد تخلت عن لغتها وعزلوها عن موضووعات الحضارة. وتواجه اللغة العربية الفصحى جملة من التحديات التي تعاني من أجلها العزلة عن الحياة اللغوية. وذلك لأن اللهجات العامية المنتشرة في الوطن العربي قد حلت محل هذه اللغة الفصيحة. فالدول العربية التي بلغ عددها اثنتين وعشرين دولة البخوعة في عضوية جامعة الدول العربية لديهم اثنتان وعشرون لهجة محلية. بل إن الدولة الواحدة قد يكون فيها أكثر من لهجة، ويتفاهم المواطنون في تلك الدولة

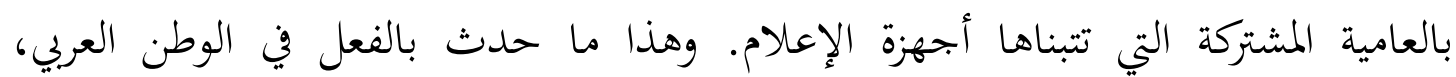
فتختلف لهجاتَم في التطبيق اليومي من الكلام ولكنهم يقتربون من اللغة الفصحى عند مستوى ثقافي معين. إضافة إلى ذلك أن المشتغلين بتدريس الطلاب في المدارس العامة استعملوا اللهجات المحلية أو اللغة العامية بل إن كثيرا من أساتذة الجحامعات في الآداب يستخدمون اللهجات المحلية أيضا. فالتحديات التي تواجتها اللغة العربية الفصحى يمكن تلخيصها فيما يلي:

$$
\begin{aligned}
& \text { • استبدال العامية بالفصحى، } \\
& \text { • تطوير الفصحى حتى تقترب من العامية، } \\
& \text { • الهجوم على الحروف العربية والدعوة إلى استعمال الحروف اللاتينية } \\
& \text { • إسقاط الإعراب في الكتابة والنطق. } \\
& \text { • الدعوة إلى إغراق العربية في سيل من الألفاظ الأجنبية. }
\end{aligned}
$$

ـ محاولة تطبيق مناهج اللغات الأوروبية على اللغة العربية ودراسة اللهجات والعامية.

\section{التطور اللغوي في العربية ومظاهره}

اتبعت اللغة العربية النهج الطبعي الذي سلكته اللغات العالمية لتجديد ثوبها وإثبات قدرغة على السيطرة للمواقف المختلفة التي تفرضها الحضارة. فاللغة العربية بقرآها وأشعارها ونصوصها باقية على الدوام. فمن خلال تلك النصوص يستطيع الإنسان أن يتصور مظاهر 
تطور اللغة. فاللغة العربية في العصر الجاهلي مطبوعة بالنزعة الحسية المادية في كل شيء،

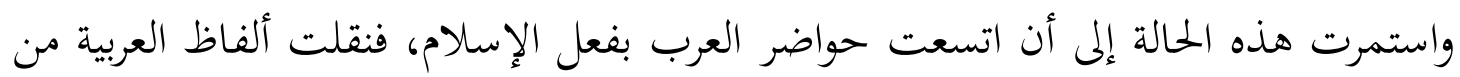

$$
\text { مواضع إلى مواضع أخر بزيادات وشرائط وضوابط معينة. }
$$

فألفاظ المؤمن والمسلم والكافر والمنافق وغيرها من الكلمات التي يحملها الإسلام مثلا،

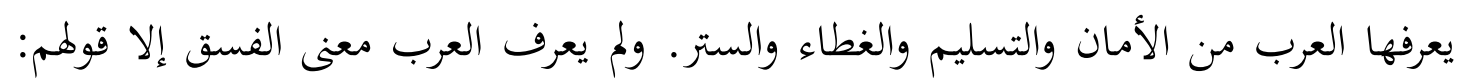

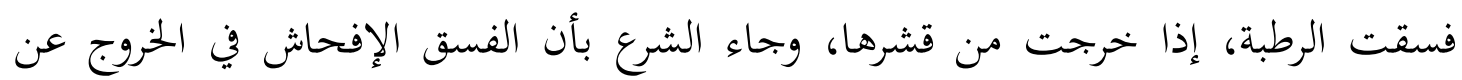
طاعة الله جل ثناؤه.

وهذا التطور اللغوي الذي حدث على اللغة العربية يمكن تقسيمه فيما يلي

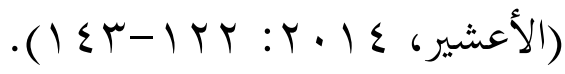

$$
\begin{aligned}
& \text { • انتقال بحال الدلالة }
\end{aligned}
$$

اللفظ إذا كثر استعماله لا يثبت على حالة واحدة، فينتقل من دلالته الأصلية إلى الى الى الـاله دلالة أخرى قائمة على المشابهة أو اعتمادا على علاقات البحاز المرسل كالسببية والمسببية وغيرك من بقية العلاقات. فهي كلها علاقات تسوغ الانتقال إلى معنى جديد لا يقطع الصلة بالمعنى القديم، مثل الرائد الذي كان في الأصل يطلق على فيلى

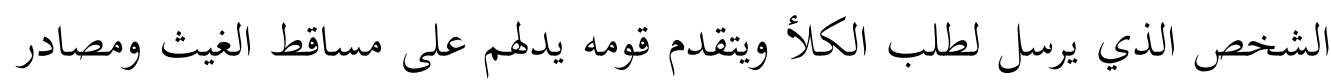

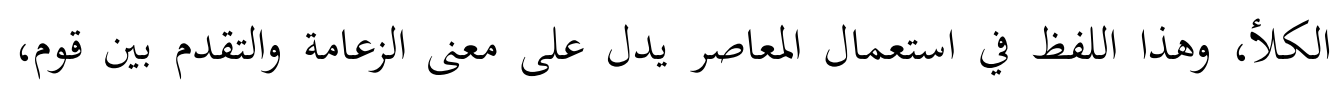
مثل: هذه فكرة رائدة، وهذا مفكر رائد بمعنى زغيم ومقدم في ميدانه.

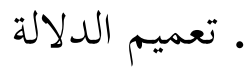

وهو انتقال المعنى الضيق إلى معنى أو معاني أكثر اتساعا، حيث إن كثرة استعمال

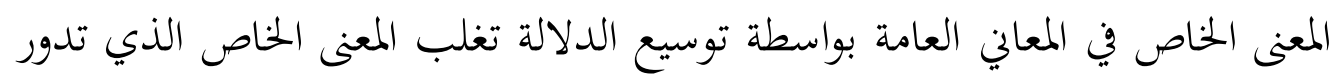
عليه الدوائر مع مرور الأيام، وذلك مثل الركب الذي يطلق على راكب البعير

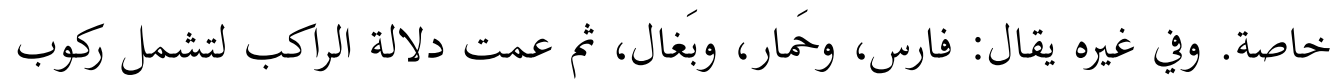

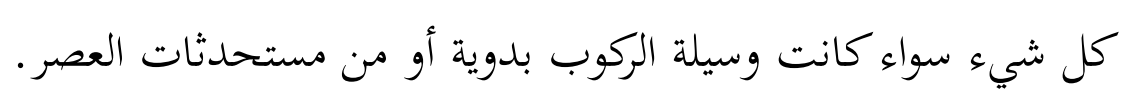

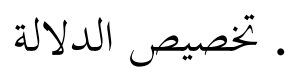


وهو عبارة من تغيرات اجتماعية تلحق بالألفاظ تبعا لحاجات البحتمع اللغوي، أو

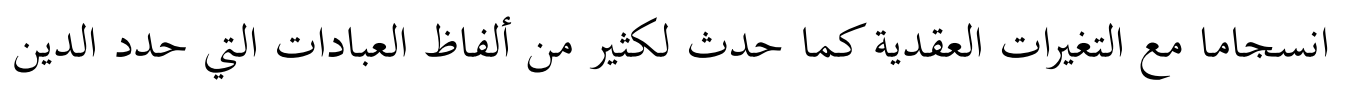
الإسلامي بحال استعمالها وخصصها بدلالات محددة، مثل الإيمان الذي تنصرف دلالته إلى الأمان على العرض والمال وتحولت إلى التصديق بكل شيء. وخصص هذا

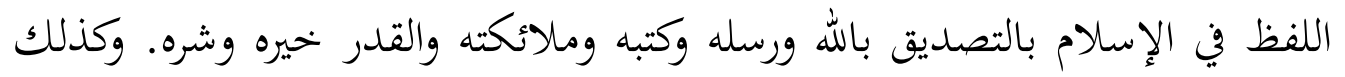

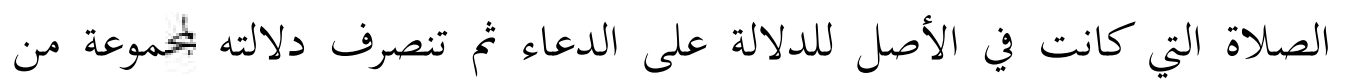
الأفعال والأقوال المبتدأة بالتكبير والمختتمة بالتسليم بشرائط وأركان مخصوصة.

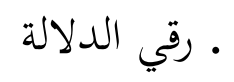

ظهور الارتقاء أو الانططاط لدلالة الألفاظ قد يكون مستمدا من السطلة الدينية أو

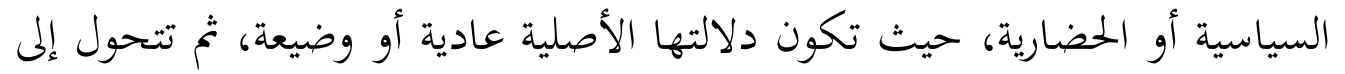
دلالة أرقى وأشرف، وذلك مثل لفظ الرسول الذي يعني بحرد شخص يرسل في مهمة

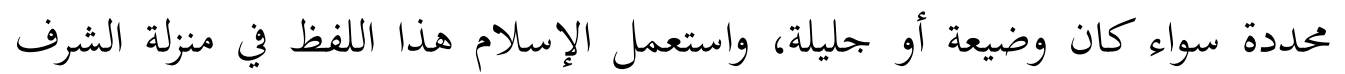
والرقي إذ خصه بشخص الرسل والأنبياء الذي حملوا الرسالة السماوية.

ـ انحطاط الدلالة

قد تلحق الحسة بعض الألفاظ على إثر تطورات الذوق في الحياة العامة، فتحل محلها ألفاظ تنسجم مع درجة التمدن والتغير الذين تصل إليهما الجماعة اللغوية. وكان للعرب مبدأ قديم يؤكد حرصهم على قلب المسميات التي لا تعجبهم إلى إلى أضدادها نظرا لانحطاط دلالتها فيجعلون المنحط منها مقبولا مثل قولمم: البصير

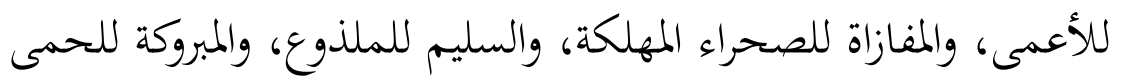

الخحلاصة

وبعد عرض هذه النقاط السابقة حول إعجاز القرآن، وفصاحته، ومفهوم الفصاحة في العربية، وأهمية اللغة العربية الفصحى وتحدياتها في العالم الواقع، والتطور اللغوي في العربية

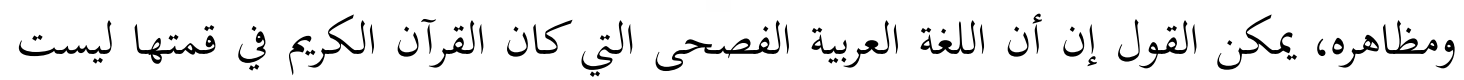
بحرد وسيلة حاملة للفكر، ولكنها فوق ذلك تمثل الدين الإسلامي، وتؤشر على الخصائص الموحدة للعروبة، وأن التطور التي حدث فيها يجب أن يسير وفق نظام محدد في أصواتها 
وصرفها وخوها ودلالاقا، وأن هذه الأنظمة ليست متساوية في الاستجابة للتطور بدليل أن

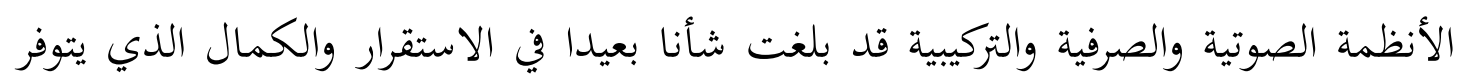
في اللغة العربية، فانفردت العربية بظاهرة الخلود التي لم تتوفر لغيرها من اللغات الإنسانية

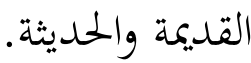

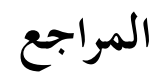

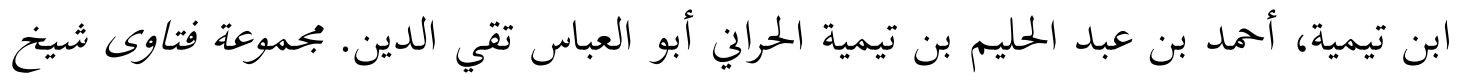

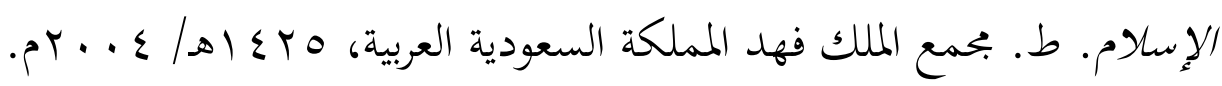

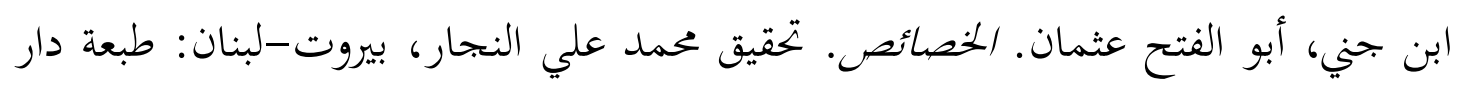
الهدى للطباعة والنشر. الطبعة الثانية.

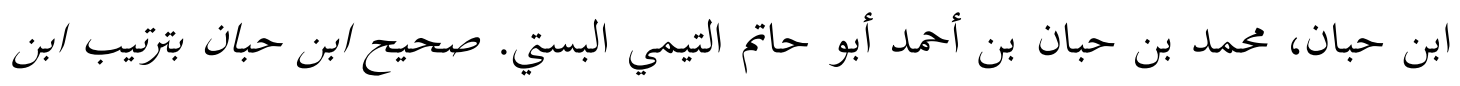

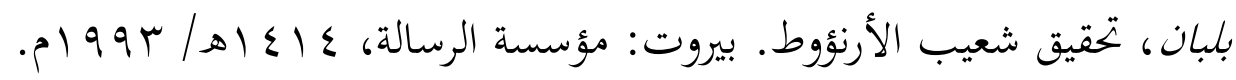

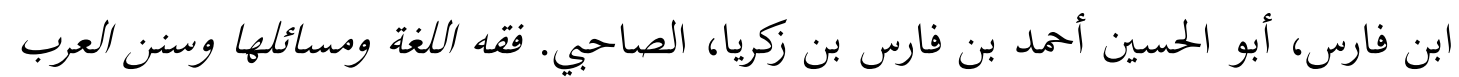

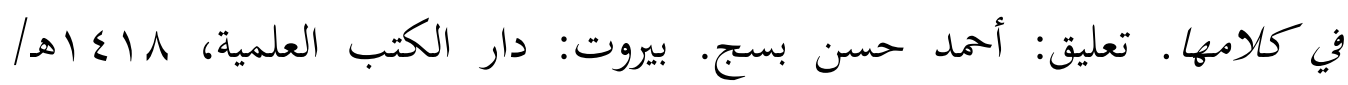
$.6199 \mathrm{~V}$

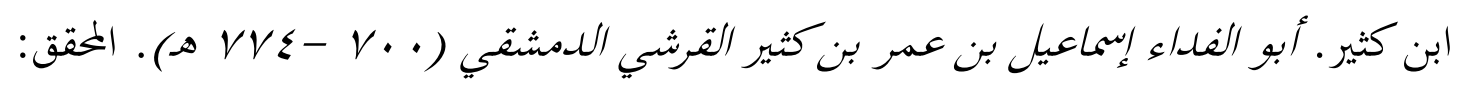

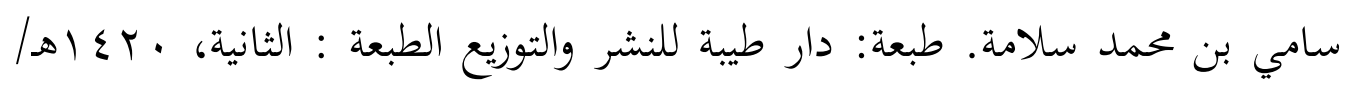
.01999

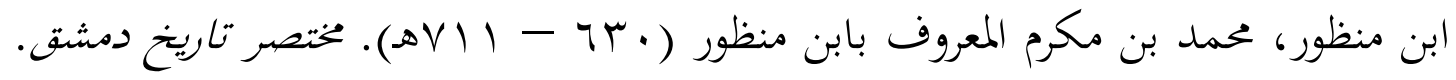

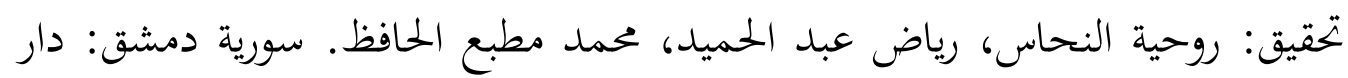

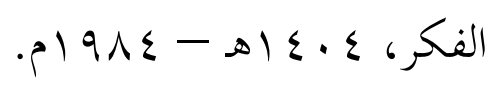

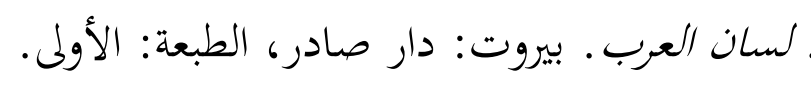

الأعشير، عبد الله آيات. اللغة العربية الفصحى نظرات في قوانين تطورها وبلى المهجور من المال

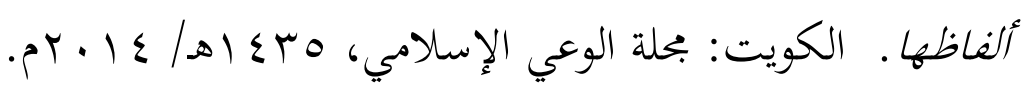

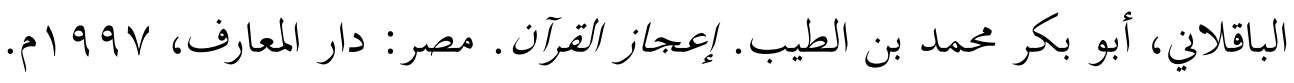


البخاري، محمد بن إسماعيل أبو عبد الله أبو عبد الله الجعفي. الجامع الصحيح المختصر.

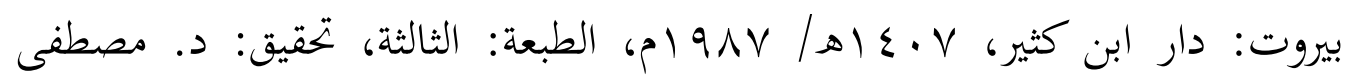

$$
\text { ديب البغا. }
$$

البغدادي، عبد القادر بن عمر. خزانة الأدب ولب لباب لسان العرب. تحقيق: عبد السلام

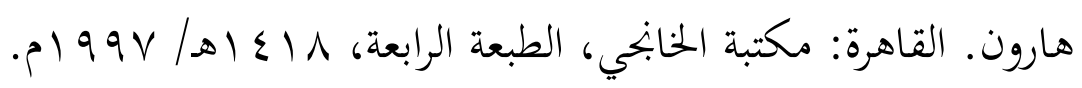

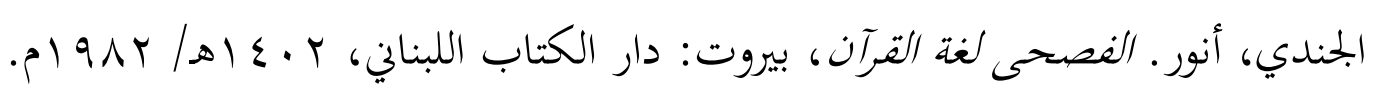

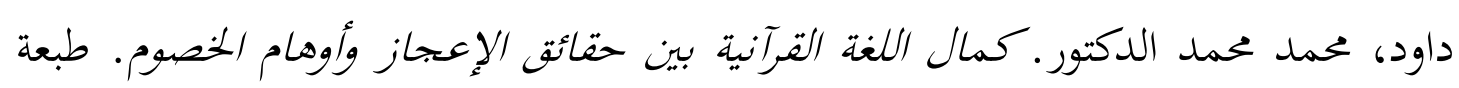
دار المنار القاهرة.

الزركشي، محمد بن بهادر بن عبد الله الزركشي أبو عبد الله. البرهان في علوم القرآن. بيروت:

$$
\text { دار المعرفة، الو أه، تحقيق: محمد أبو الفضل إبراهيم. }
$$

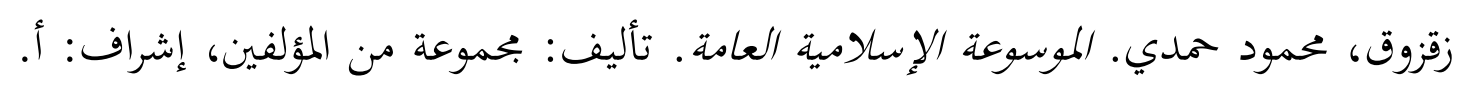

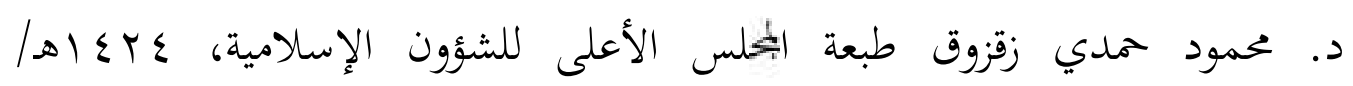

$$
\text { pr..r }
$$

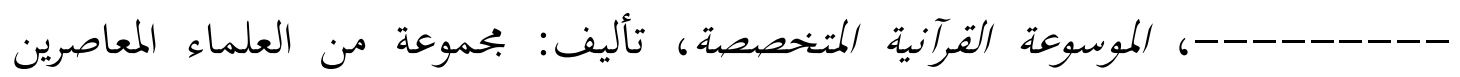
إشراف: أ. د. محمود حمدي زقزوق، طبعة البحلس الأعلى للشؤون الإسلامية وزارة

$$
\text { الأوقاف مصر. }
$$

السيوطي، جلال الدين بن عبد الرحم. المزهر في في علوم اللغة وأنواعها. تحقيق: محمد أحمد

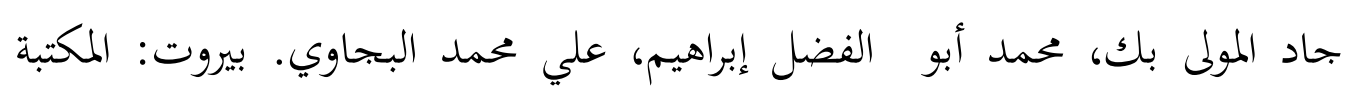

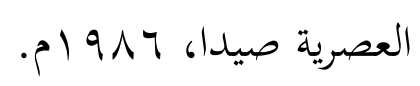

الإتقان في علوم القرآن. لبنان: دار الفكر، 7 إعاهـا

$$
\text { 1997 19، الطبعة: الأولى، تحقيق: سعيد المندوب. }
$$

الشيرازي، أبو إسحاق إبراهيم بن علي. اللمع في أصول الفقه. بيروت: دار الكتب العلمية،

$$
\text { . } 1910-81 \leqslant \text {. } 0
$$

ضيف، شوقي. تاريخ الأدب العربي العصر الجاهلي. القاهرة: دار المعارف، الطبعة الحادية

$$
\text { عشرة. }
$$


الغزالي، أبو حامد محمد بن محمد الغزالي الطوسي. المستصفى في أصول الفقه. بيروت: دار الكتب العلمية س إع اهـ، الطبعة: الأولى، تحقيق: محمد عبد السلام عبد الشافي.

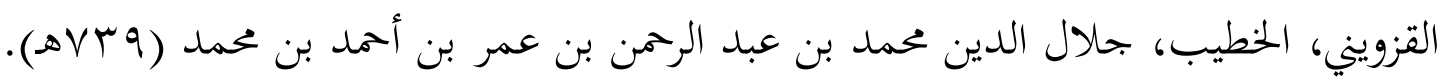

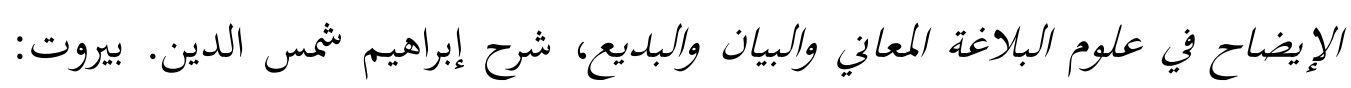

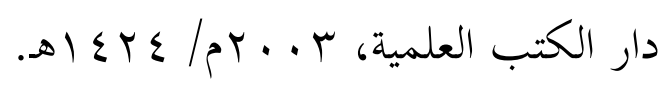

الماوردي، القاضي أبو الحسن علي بن محمد بن حبيب البصري. الحاوي في فقه الشافعي.

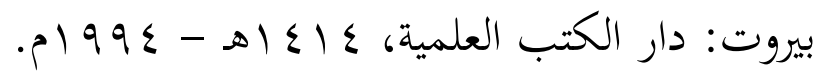

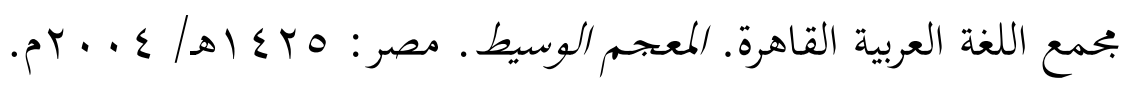

